\title{
SciPro Matching: ICT Support to Start a Quality Thesis
}

\author{
Henrik Hansson, Jan Moberg, Ranil Peiris \\ Department of Computer and Systems Sciences, Stockholm University, Sweden
}

\begin{abstract}
This article focuses on how to empower the initiation stage in the thesis supervision process with information and communication technology. Starting a large number of theses with available resources based on creative ideas is a challenging task. Another challenge is to connect student's theses with industry's interests. The SciPro ICT support system for thesis supervision was developed over a five-year period. The most important task in the thesis initiation stage is matching students, supervisors, and ideas. Business partners and administrative staff are other stakeholders who should interact in this process. Although the choice of an idea is the responsibility of students, and seems simple, it in fact requires a series of academic and administrative support processes. There is a lack of IT systems specifically address thesis supervision, especially the initiation stage. The SciPro system was constructed to bridge this gap. The initiation stage is the foundation of a quality thesis, and it highly affects the quality of a thesis. The research approach was based on a design science method. Prototyping, testing, demonstrations, and user evaluations were conducted throughout. Data collection methods for user evaluations included interviews, observations, focus-group discussions, and $\log$ data. This paper presents the SciPro IT system, which was developed to support the start of quality theses. This system adds value, saves time and increases the quality of the thesis initiation stage. The process implemented rewards supervisors and students by providing a high degree of freedom, control, and selection of relevant topics. It enables both automatic processes for previously timeconsuming work and qualified manual operations which can be controlled by administrators according to their needs. SciPro can also be used to improve industry-university collaboration on thesis production.
\end{abstract}

Index Terms - Thesis initiation, supervision, matching, business, university, ideas, innovative, management, IT

\section{INTRODUCTION AND AIM}

$\mathrm{F}$ om a small seed, a mighty trunk may grow (Aeschylus, 526-456 BC). In research, ideas are seeds that can produce fruitful trees, and without good ideas all scientific work is fruitless. Students starting to write their theses (Bachelor's, Master's, or $\mathrm{PhD}$ ) face the same challenge as other researchers: how can I find a good topic? where shall I start? The idea needs to be relevant, interesting, and manageable within the available time frame.

Henrik Hansson (Associate Professor) is with the Department of Computer and Systems Sciences, Stockholm University - Sweden and Coordinator of ICT4D research and Senior Researcher in Technology Enhanced Learning (TEL). (e-mail: henrik.hansson@dsv.su.se)

Jan Moberg (IT Manager) is with the Department of Computer and Systems Sciences Stockholm University - Sweden and IT Director. (email: jan.moberg@dsv.su.se)

Colombage Ranil Peiris (PhD Student) is with the Department of Computer and Systems Sciences, Colombo Sri Lanka and Stockholm University, Sweden, and Senior lecturer in University of Sri Jayewardenepura, Sri Lanka (e-mail: ranil@dsv.su.se)
The initial part of a research project, creative idea generation, is not subject to any methodological procedure. Ideas are created in many diverse ways. Personality, experience, an open mindset, and curiosity play a role. Structure and stimuli also help the process. There needs to be a balance between freedom and structure in order to facilitate good ideas. A student's thesis is a sustainable way of promoting industry-university collaboration through realworld projects. It also offers a possibility of selecting realworld projects and real project ideas from industry, which is beneficial for both university and industrial stakeholders.

A successful thesis project contains three steps: (1) project initiation, (2) supervision, and (3) utilization. In the initiation step, one or more students should select a research problem and then one or more supervisors should be assigned to the project. Then the supervision process starts. Supervisors, students, and other interested parties (reviewers and peers) communicate with each other until the completion of the project. Finally, the thesis findings should be published for the benefit of society (utilization). There are a number of issues and opportunities in the project supervision process that should be addressed to enhance the quality of this process.

This article focuses on the first step, project initiation. If the initiation is not carefully elaborated, it will adversely affect project completion. There are several problems and opportunities, which are usually not considered in the project initiation phase. For a successful thesis, three components should be properly matched: the project idea, one or more students, and one or more supervisors. There is a risk otherwise that projects will not really benefit society. Students may select any kind of research project that satisfies the basic course requirements. Supervisors tend to accept students' projects if they fit into their own knowledge area, and they do not have enough time to guide them in choosing a useful project. Additionally, students and supervisors lack the resources and time to develop a dynamic information link to identify current industry issues. The duty of university administration is limited to registration and course administration. Although industry and society can provide research questions constituting useful points of departure for thesis projects, there is no proper link between industry and its university partners. Hence, the majority of project ideas will stay on desks as memos without ever reaching the appropriate community. Similarly, valuable research findings remain in academic reports because of the lack of proper links between industry and university.

Aim: To describe and analyse the information and communication system support for the thesis initiation stage. 


\section{RELATED WORK}

Initiating a thesis is a time-consuming and complex process. Students have to access many types of information sources and consider a number of influencing factors [1] such as the tasks handled by an administrator. According to Isaak and Hubert [2], 'good' thesis topic selection is a critical thinking and filtering process that should be done by the student with advice from a supervisor. The chosen topic will affect the success of the project, so its selection is very important [3][4] and should be managed in the same way as other steps in the process. Almost all theses management information systems ignore this aspect or fail to provide enough support for it. There are only a few research studies of online thesis supervision systems, and a brief overview is presented in the next section.

Richard [5] described a research supervision system project implemented at Makerere University in Uganda. Although the system diagram showed that supervisors' specializations were listed and students could submit concept papers, there was no proper matching system or 'idea bank' concept (see Section IV) to support the project initiation step. According to the author, the system was an intranet system and was unable to satisfy essential requirements.

Colbran [6] implemented a supervision support system for $\mathrm{PhD}$ supervision using collaborative supervision of doctoral theses. A supervision cell (website for supervision support) was implemented by means of an action research approach. The website had seven main elements; (1) project management, (2) reflective journal, (3) exercises, (4) discussion forum, (5) private correspondence files, (6) resource websites, and (7) course material database. In this project, ICT was not used for the idea-matching process.

The Department of Management at the Durban University of Technology (DUT), South Africa [7] implemented a web-based (WebCT) system for postgraduate research management as a blended approach in 2005 and 2006. The findings showed that it improved the supervision process, reduced the administrative workload of the supervisor, and created a dynamic record of the supervision process. The results to date imply that traditional supervision practice needs to be revisited and modified to include digital procedures. The research study was, however, focused mainly on communication and data recorded with ICT and ignored the initial stage of the thesis process.

Another research study by MacKeogh [8] conducted at Dublin City University found that it was possible to use learning methodologies to provide a supportive environment for students embarking on undergraduate research. Moodle was used as the technical system and a conference module for communication between students and supervisors. The paper outlined the approach to research supervision adopted in a distance education psychology module, which combined online supervision, face-to-face meetings, and peer supervision. This research did not consider the matching function and its complexity.

Additionally, learning management systems (LMS) do not specifically support the thesis supervision process, especially the initial matching part of the process. Although there are some well-developed LMS in the e-learning industry, they do not manage thesis supervision as a special module, although there are a few tools that can be used with limited functionality [8]. The support offered by standard LMS for the thesis supervision process is not adequately developed or specific enough.

Foster and Gibbons [3] highlighted the importance of selecting a good title as a way to increase research interest. They noted that poor choice of a topic and problems with developing a topic were obstacles to production of a good research paper. Lei argued that the selection of a thesis topic was a time-consuming and complex process, and stated that 'Students have to access many types of information sources and have to consider a number of influencing factors' [1].

Hansson and colleagues [9] originated discussion on the use of ICT for thesis supervision. The important point of this study was that they identified four stakeholders and highlighted the importance of collaboration among the stakeholders for a quality thesis. Aghaee and others [10] studied the issues that emerged during the thesis process and noted that one of the main issues was project initiation.

With regard to the importance of topic selection, Harrison and Whalley [4] stated the following in the light of their survey results on undergraduate research:

'From both the staff and student perspective, deciding on the right topic of study is fundamental. Students recognize that the topic should be something that really interests them and will motivate them for sustained study. Students valued the freedom to choose their topic of study yet also identified that a failure to get it right threatened further study'.

The Council of Graduate Schools (1990), cited in Donald and colleagues [11, p. 74], suggested that there were two major factors in the supervision of graduate research students. The first and more important had to do with creativity and involved the ability to select problems, to stimulate and enthuse students, and to provide a steady stream of ideas.

\section{A. What is supervision?}

Supervision is a subtype of pedagogy, and it basically focuses on one or a few students per supervisor. Supervision refers here to processes that academics use to support students' learning as defined by Maxwell and Smyth [12]. Generally, 'advisor' is the term used in North America and 'supervisor' in those countries with a British higher education tradition. Henceforth, the terms supervisor/supervising are used.

Connell [13] suggested that supervision was one of the most complex and problematic pedagogical methods and led to a high dropout rate [14]. She observed that both students and supervisors failed to identify supervision as a method of teaching. She argued that it was genuinely a complex teaching task and, like other forms, raised questions about curriculum, method, teacher/student interaction, and educational environment. It also required a substantial commitment of time and energy. 


\section{METHODOLOGY}

Sherman and Webb [14] observed that three concepts were at the core of qualitative methods: holism, context, and validity. In fact, the need to achieve and increase validity was the reason for selecting a qualitative method when researching certain topics where it was not possible to gain valid results by using a quantitative approach. Figure 1 below outlines the differences between types of research questions and the connection to research approaches. If the issue is how people 'think', observations of behaviour are not enough. One needs to talk (interview, discuss) in order to understand attitudes. What people say they want is not always what they actually do, however, so actual observation of behaviour is also needed.

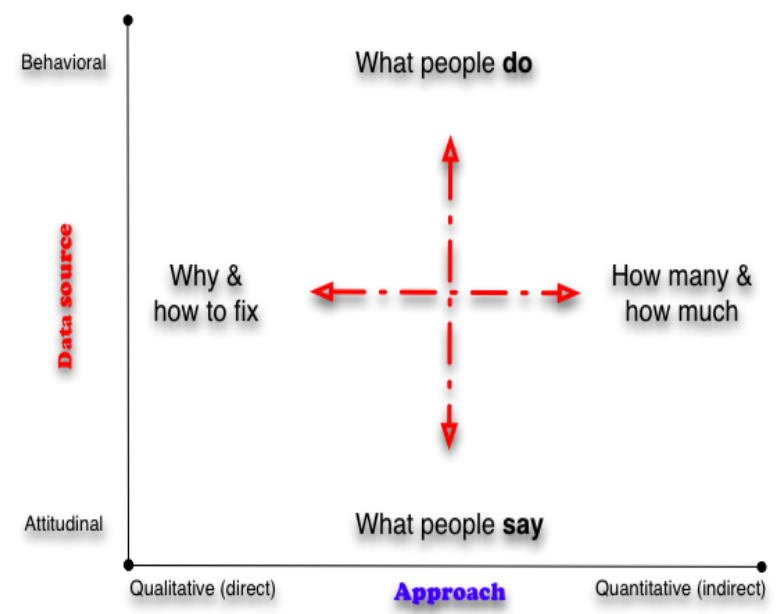

Fig. 1 Overview of research approaches and connection to types of research questions (adapted from Rohrer, 2008) [16].

The SciPro system, which was developed at Stockholm University, was selected as a case study. McCaslin and Scott defined case study research as 'an in-depth study of a bounded system with the focus being either the case or an issue illustrated by the case(s)' [15]. Creswell and colleagues [16] defined it as

'a qualitative approach in which the investigator explores a bounded system (a case) or multiple bounded systems (cases) over time, through detailed, in-depth data collection involving multiple sources of information (e.g., observations, interviews, audiovisual material, and documents and reports),

and reports a case description and case-based themes'. Furthermore, they discussed three variations in terms of intent: the single instrumental case study, the collective or multiple case studies, and the intrinsic case study. A single instrumental case study was selected. In such a case study [17], the researcher focuses on an issue or concern, and then selects one bounded case to illustrate the issue.

Research can be very generally defined as an activity that contributes to the understanding of a phenomenon [18]. Niiniluoto emphasized that sciences that explain and interpret the world were largely studied by philosophers
[19]. He suggested paying attention to sciences which change the world and that design science was a methodology that was used to understand complex phenomena with the aid of an artefact. Hevner and Chatterjee [20, p. 5]] defined design science research (DSR) as follows:

'Design science research is a research paradigm in which a designer answers questions relevant to human problems via the creation of innovative artifacts, thereby contributing new knowledge to the body of scientific evidence. The designed artifacts are both useful and fundamental in understanding that problem'.

This paper will answer questions related to how the thesis process can be improved. The theme of this research is how ICT can be used for supporting the initiation stage. The SciPro case was combined with design science to address the research question.

Peffers and colleagues [21] highlighted six steps in design science research methodology with reference to seven papers published in the field. This paper follows these steps with the case study approach to discuss the importance of an ICT support system for the thesis initiation stage.

- Activity 1: Problem identification and motivation

- Activity 2: Defining the objectives for a solution

- Activity 3: Design and development

- Activity 4: Demonstration

- Activity 5: Evaluation

- Activity 6. Communication

During a five-year period, the authors had many interactions with staff and students both informally (daily conversations, drop-in, problem-solving, etc.) and formally (development meetings, trials, workshops, evaluations, specific interviews, questionnaires, interaction with students as supervisors, etc.). This interaction accumulated information about stakeholder perceptions, needs, attitudes, and problems. Based on these interactions, the system was developed and redesigned several times. There was not always consensus between students, supervisors, and administrators about how to do it. Furthermore, among such stakeholders there were several opposing views and interests. The authors needed to accommodate expressed needs so that most people were satisfied, and selected the procedures believed to provide the best quality and efficiency.

Regarding context, the system was designed specifically for the Department of Computer and Systems Sciences at Stockholm University, Sweden. This meant that it was adapted to the Swedish model of higher education (requirements according to the Higher Education Act and other laws and regulations; see Swedish National Agency for Higher Education) [22]. The authors adapted the system to: 


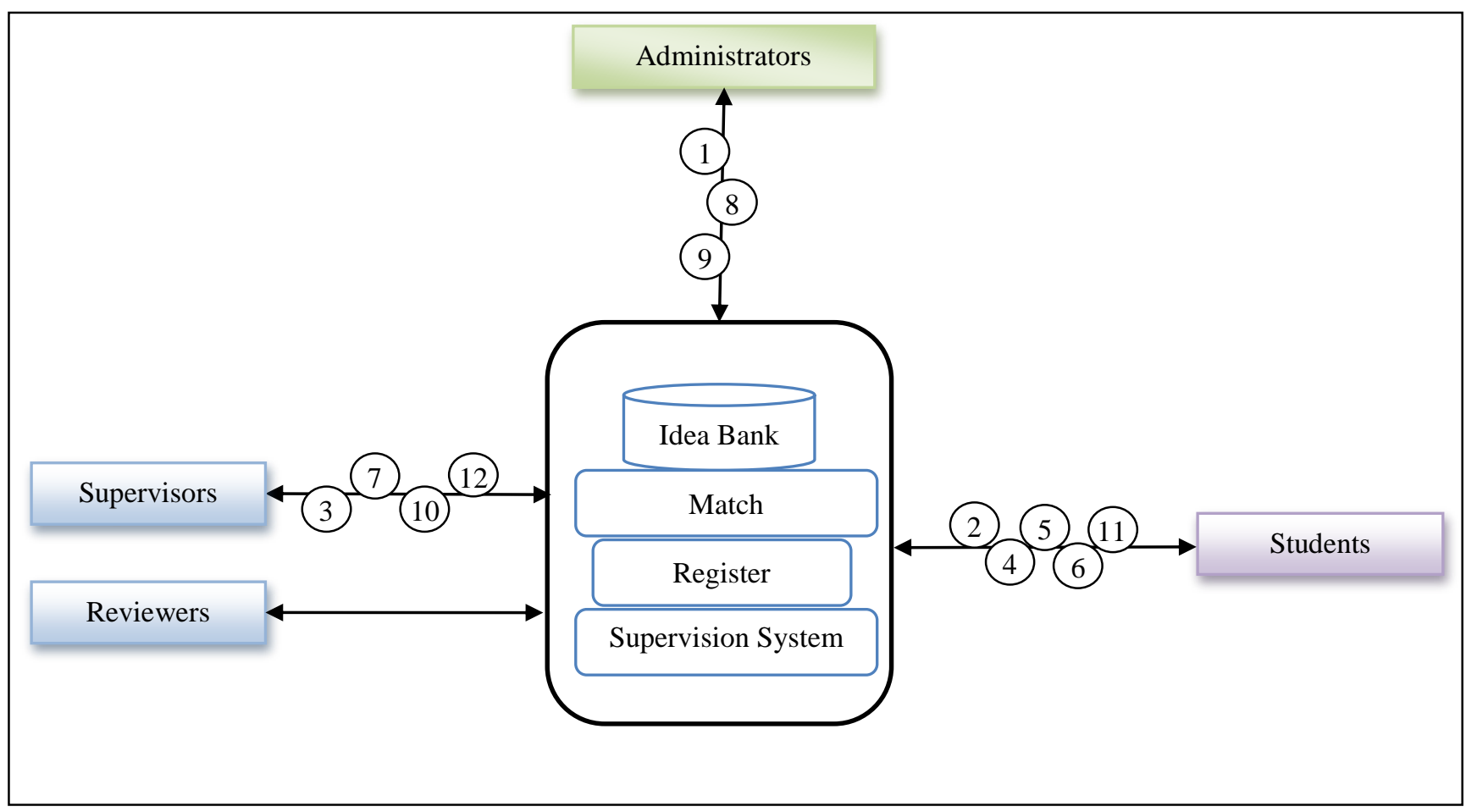

Fig. 2 Matching procedures: Functions 1-12 outlined above are explained in the article text.

- The student profile at the department

- The staff and organization at the department

- The IT infrastructure already available at the department and IT systems provided by Stockholm University at the central level, such as digital access to library services, etc. In fact, the matching system was accessed through single sign-on and integrated with more than 30 different IT systems.

Multiple data collection methods were used: interviews, observations, focus group discussions, workshops (with demonstrations, prototypes, design mock-ups, etc.) and log data. Additionally, emails and drop-in, and face-to-face support sessions generated critical issues and identified user experiences for consideration.

\section{RESULTS AND DISCUSSION}

As a result of continuous development, SciPro version 3 provides wide-ranging facilities for the project initiation stage. Hansson and colleagues [23] discussed matchmaking facility evolution in SciPro (versions 1 and 2). As illustrated in Figure 2, this stage consisted of four interrelated systems; (1) register (DAISY), (2) idea bank, (3) match, and (4) the supervision process. In version 1 , the register system and supervision process system were integrated and the others were separate systems. In version 2 all the systems were integrated except the idea bank. The preceding supervision support system was developed in parallel with another system with resources containing information, instructions, learning material, templates, grading criteria, and FAQs for both thesis writing students and supervisors. A unification process and considerable system maturity took place during a five-year period that significantly increased the efficiency, simplicity, transparency, and quality of the initial phase of the thesis work.

\section{A. Registry}

It was very important to match the new system with the existing information system for several reasons. Technically it was easy to implement and reuse data and resources. From a user's perspective, it was essential to get his/her support and to reduce resistance to the new system. SciPro was designed to use the general information system for student and supervisor registration. Also, this integration was essential to reduce the workload of the thesis administration staff. Figure 2 shows the registration system within SciPro. Registered students in DAISY could access the system for thesis supervision. The process started when an administrator activated an application period in the system. See Figure 2: number 1.

\section{B. Idea Bank}

The idea bank subsystem facilitated the storage of ideas from potential idea sources. Figure 3 illustrates the concept with several idea sources. The institution could decide which sources were going to link with the idea bank as a source: see Figure 2: number 2 where students uploaded their thesis project ideas. In the current practice, idea creation was limited to specific admission times in the academic calendar. A flexible thesis start could be introduced, opening admissions for the whole year. This eliminated the waiting time to register a new thesis and helped to get more industry projects into the system. The management of staff time needed a new business model to incorporate such flexibility, however. Table 1, column 3 shows the registered ideas for the last semesters 


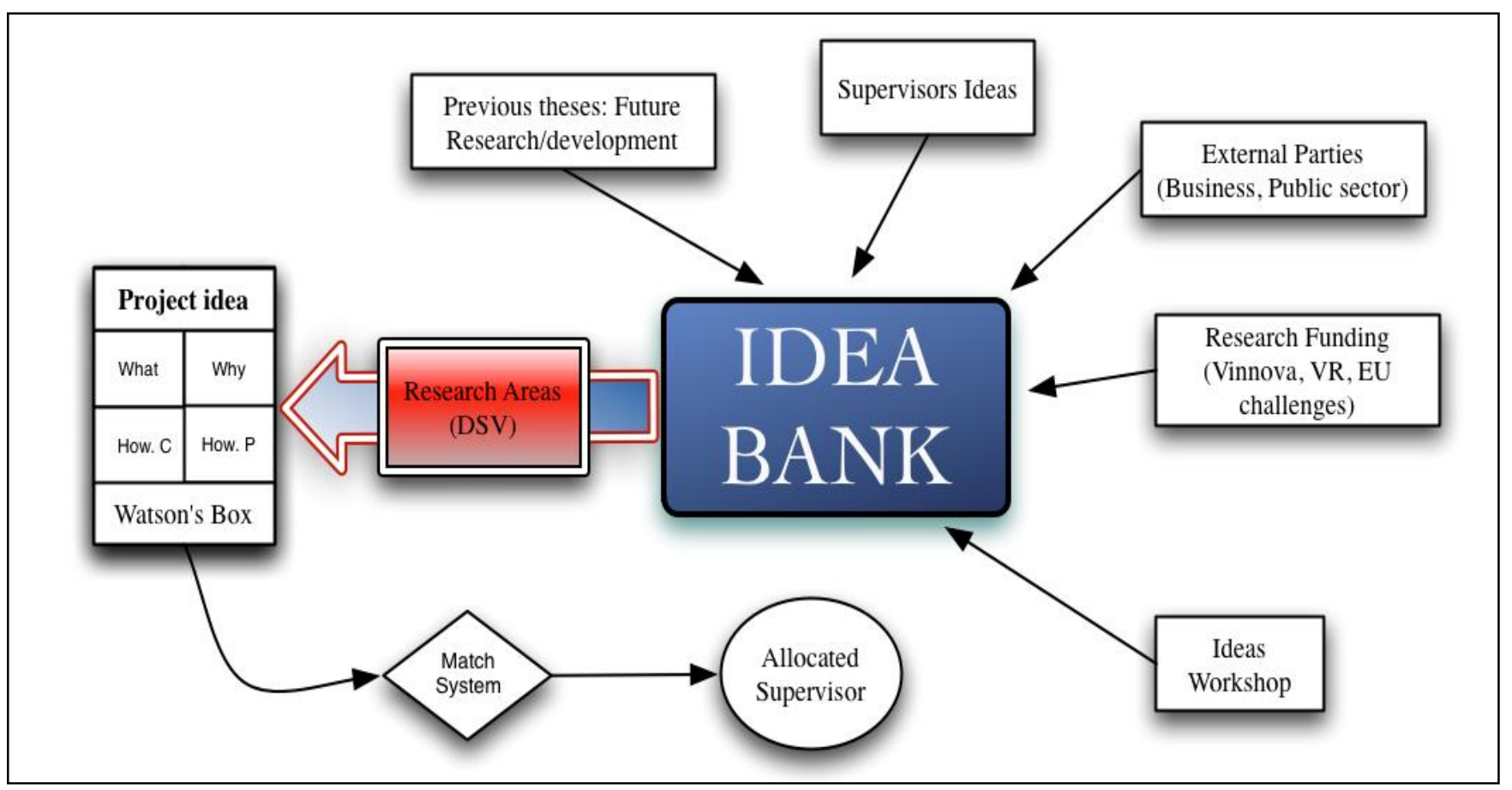

Fig. 3 Idea Bank

Table 1. Number of supervisors, students and project ideas matched regarding thesis work 2010-14

\begin{tabular}{|c|c|c|c|c|}
\hline $\begin{array}{l}\text { Per- } \\
\text { iod }\end{array}$ & $\begin{array}{l}\text { Num- } \\
\text { ber of } \\
\text { super- } \\
\text { visors }\end{array}$ & $\begin{array}{l}\text { Number of } \\
\text { students }\end{array}$ & $\begin{array}{l}\text { Number } \\
\text { of ideas in } \\
\text { idea bank }\end{array}$ & $\begin{array}{l}\text { Matched } \\
\text { thesis } \\
\text { project } \\
\text { ideas* }\end{array}$ \\
\hline $\begin{array}{l}2010 \\
-11\end{array}$ & 81 & $\begin{array}{l}311 \text { (Master) } \\
390 \\
\text { (Bachelor) }\end{array}$ & $\begin{array}{l}\text { Autumn } \\
\text { 2010: } 0 \\
\text { Spring } \\
\text { 2011: } 5 \\
\text { Autumn } \\
\text { 2011: } 200\end{array}$ & $\begin{array}{l}300 \\
\text { (Master) } \\
220 \\
\text { (Bachelor) }\end{array}$ \\
\hline $\begin{array}{l}2011 \\
-12\end{array}$ & 46 & $\begin{array}{l}175 \\
\text { (Bachelor) }\end{array}$ & $\begin{array}{l}\text { Spring } \\
2012: 224\end{array}$ & $\begin{array}{l}95 \\
\text { (Bachelor) }\end{array}$ \\
\hline $\begin{array}{l}2012 \\
-13\end{array}$ & 77 & $\begin{array}{l}113 \text { (Master) } \\
405 \\
\text { (Bachelor) }\end{array}$ & $\begin{array}{l}\text { Spring } \\
\text { 2013: } 221\end{array}$ & $\begin{array}{l}113 \\
\text { (Master) } \\
217 \\
\text { (Bachelor) }\end{array}$ \\
\hline $\begin{array}{l}2013- \\
14\end{array}$ & 94 & $\begin{array}{l}90 \text { (Master) } \\
406 \text { (Bachelor) }\end{array}$ & 290 & $\begin{array}{l}90 \\
\text { (Master) } \\
215 \\
\text { (Bachelor) }\end{array}$ \\
\hline
\end{tabular}

Students sent their ideas to the matching system in a short overview format. The template suggested by Watson was used, [24] referred to as a 'Watson's box' (see Table 2). This format provided a holistic picture of the general idea, methods, and practical aspects of a thesis project. Students also labelled their project idea with keywords, a research area, the languages they could receive supervision in, and a preliminary title. Students could choose to label their project idea with a confirmed supervisor (a supervisor who had agreed to supervise the project), a preferred supervisor (when a student wanted a certain supervisor, but had not yet agreed it with the supervisor), and an external supervisor (from an external organization). These steps provided enough information at this stage and were used for the allocation of a project idea to a suitable supervisor who is active within a particular research area.

Students' project ideas were matched in the system with available supervisors, who had indicated their research activities with keywords in the match system (see Figure 2: number 3 for supervisors' ideas for thesis topics). Supervisors were of course more interested in supervising students within their research field than otherwise. Students, however, did not know what the supervisors were researching or their particular foci and projects. From a quality perspective, it was also very important to connect research with education, and the thesis work was very suitable for this purpose. The student received a meaningful context for the thesis work and the supervisor received an additional collaborator for current research activities. To facilitate this effect, the authors modified the system to accommodate supervisors' ideas for theses. Initially, as seen in Table 1 above, the ideas from supervisors were few but as soon as the users realized the potential and followed a new policy that stated 'each supervisor needs to create at least three supervisor ideas (thesis topics) for the idea bank', the idea bank began to be beneficial. Since not all supervisors were on duty every semester and they had different targets (the number of theses a supervisor could supervise in an application period), the policy was changed to 'at least the same amount of supervisor ideas as the supervisor has targets in the current application period' (see Figure 4). Two hundred twenty seven supervisor ideas were available for students, and a total of 457 supervisor ideas were created between September 2012 and December 2013). Two hundred and fifty of the ideas were created for Bachelor's and 207 for Master's degrees. The aim was to create a pool of ideas not only from supervisors but also from other sources (see Figure 3). 
Table 2 Structure for a student's project idea (Watson's box).

\begin{tabular}{|c|c|}
\hline What? & Why? \\
\hline $\begin{array}{l}\text { What puzzles and } \\
\text { intrigues me? } \\
\text { What do I want to know } \\
\text { more about or understand } \\
\text { better? }\end{array}$ & $\begin{array}{l}\text { Why is this of enough } \\
\text { interest for the library } \\
\text { shelves or my organization? } \\
\text { Is it a guide to practitioners } \\
\text { or policy- makers? }\end{array}$ \\
\hline $\begin{array}{l}\text { What are my key research } \\
\text { questions? }\end{array}$ & $\begin{array}{l}\text { Is it a contribution to } \\
\text { knowledge? }\end{array}$ \\
\hline How - conceptually? & How - practically? \\
\hline $\begin{array}{l}\text { What models, concepts, } \\
\text { and theories can I draw } \\
\text { upon? } \\
\text { How can I develop my } \\
\text { own research, questions } \\
\text { and create a conceptual } \\
\text { framework to guide my } \\
\text { investigation? }\end{array}$ & $\begin{array}{l}\text { What research methods and } \\
\text { techniques shall I use to } \\
\text { apply my conceptual } \\
\text { framework (to both gather } \\
\text { and analyse evidence)? How } \\
\text { do I gain and maintain } \\
\text { access to information } \\
\text { sources? }\end{array}$ \\
\hline
\end{tabular}

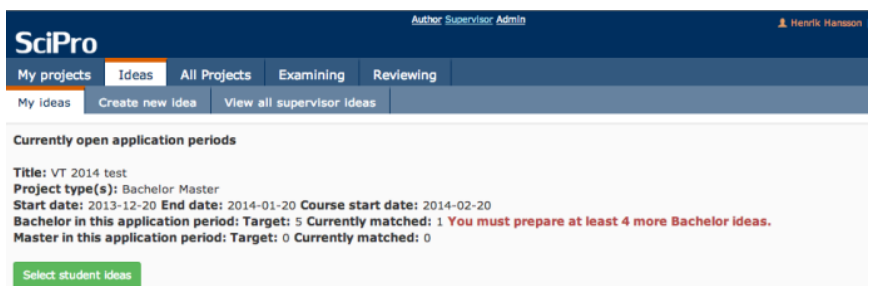

Fig. 4 Supervisor must prepare ideas

An important new aspect was that students were informed one semester before the thesis course started that they needed to come up with a project idea in the form of a 'Watson's box' before the deadline in order to find a supervisor (see Figure 5). Since time was needed to generate good ideas, this 'thinking time' significantly improved the suggested thesis topics. It also saved time when the thesis course actually started because the students already had an idea and a prototype plan as well as an informed and prepared supervisor. Also, students might have wanted to investigate opportunities to connect their thesis work with a business need, and this connection needed to be developed in advance. The actual project plan was developed in detail together with the supervisor when the course started. In some cases, the specific project plan was an elaboration of the project idea, and in other cases it was based on the supervisors' advice and knowledge, which might be a radically different plan.

\section{The Matching System}

After collecting ideas, the next step was matching supervisors, ideas, and students to form projects. The idea bank consisted of ideas, students, and supervisors, and these elements had to be matched to start a good thesis. At the Bachelor's level an additional step was required for pairing students for a group thesis. At the Bachelor's level students wrote together in pairs but some students did not know other students willing to co-work on a thesis with a topic in which they were jointly interested. A matchmaking forum was needed, and it needed to be as automatized as possible because supervisors or administrators did not have the time or knowledge to match students with similar interests. See Figure 2: number 4, where students used the project partner tool to find a partner for projects. The authors managed to find a quick and dirty solution by reusing a student forum built for social networking. It had a different layout but did the work. See Figure 6 There were 112 messages in the project partner portal from September 2011 to January 2014
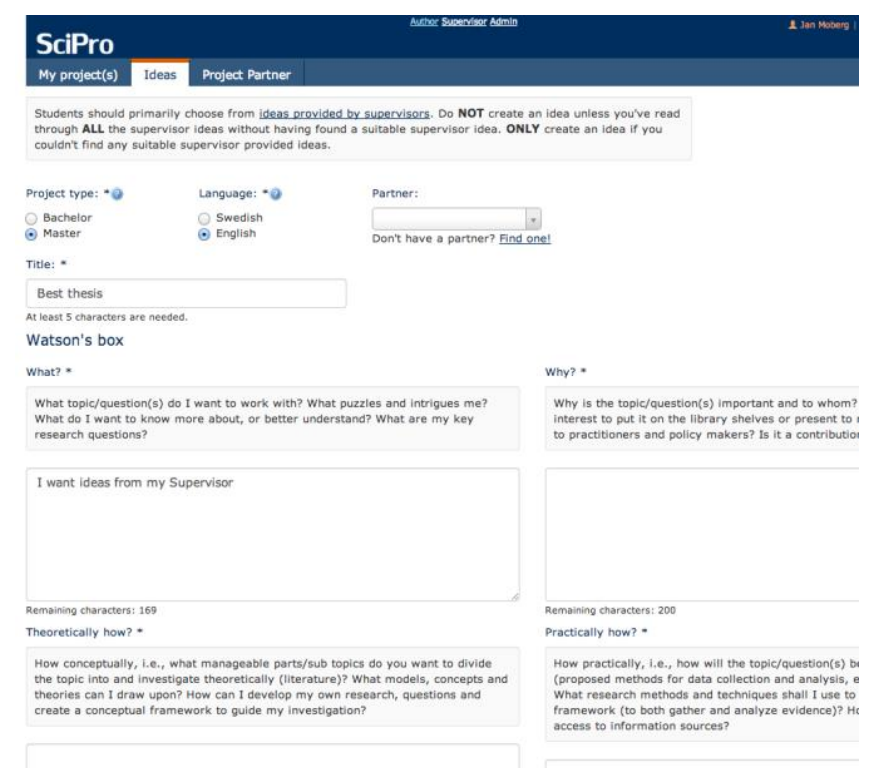

Fig. 5 Screen shot ('Watson's box'): structure for project idea

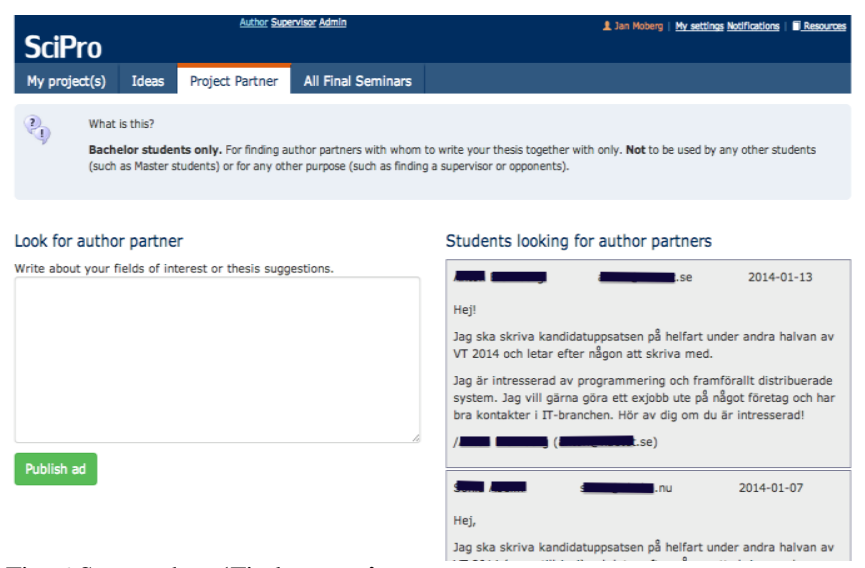

Fig. 6 Screen shot: 'Find partner'

Exemptions were needed for other reasons than not finding a partner with whom to write a joint thesis. For instance, circumstances might dictate writing alone, or a student might need exemptions because of different educational background See Figure 2: number 5. Exemptions.

In version 3, the matching between students and supervisors was more direct and used several methods. In the first and second methods, students and supervisors selected ideas by themselves and hence they could be considered as direct selection methods. Two other methods are indirect methods. All methods are explained in the table 3 and immediately below. 
Table 3. Student-supervisor matching procedure in SciPro and its pros and cons

\begin{tabular}{|l|l|l|}
\hline Method & Pros & Cons \\
\hline $\begin{array}{l}\text { Student } \\
\text { selects }\end{array}$ & $\begin{array}{l}\text { Supervisor } \\
\text { motivated (their } \\
\text { idea). No middle } \\
\text { man. }\end{array}$ & $\begin{array}{l}\text { Not enough supervisor } \\
\text { ideas for all students. } \\
\text { Sometimes students } \\
\text { cannot find an } \\
\text { interesting idea. }\end{array}$ \\
\hline $\begin{array}{l}\text { S) } \\
\text { or } \\
\text { selects }\end{array}$ & $\begin{array}{l}\text { Supervisors } \\
\text { motivated (they } \\
\text { choose the idea). } \\
\text { No middle man. }\end{array}$ & $\begin{array}{l}\text { Supervisors do not } \\
\text { think they have time to } \\
\text { choose student ideas }\end{array}$ \\
\hline $\begin{array}{l}\text { 3) } \\
\text { muto } \\
\text { match }\end{array}$ & $\begin{array}{l}\text { Fast, impersonal, } \\
\text { can be done by } \\
\text { administrative } \\
\text { staff with no } \\
\text { special skills }\end{array}$ & $\begin{array}{l}\text { Hard to find good } \\
\text { matching criteria, } \\
\text { Students often choose } \\
\text { wrong research area } \\
\text { and/or keyword }\end{array}$ \\
\hline $\begin{array}{l}\text { A) } \\
\text { Adminis } \\
\text { assigns }\end{array}$ & $\begin{array}{l}\text { Handles all kinds } \\
\text { of problems like } \\
\text { too few } \\
\text { supervisors in a } \\
\text { research area and } \\
\text { special } \\
\text { prerequisites. }\end{array}$ & $\begin{array}{l}\text { Middle man } \\
\text { involvement, high } \\
\text { workload. Need an } \\
\text { administrator with a } \\
\text { good knowledge of all } \\
\text { supervisors. }\end{array}$ \\
\hline
\end{tabular}

\section{1) Student selected}

Students could be matched directly with a supervisor if they selected a supervisor's idea in the idea bank. See Figure 2: number 6. Students could select ideas from a list uploaded by supervisors.

\section{2) Supervisors selected}

Supervisors could select students directly based on their project ideas or by prior agreement (see Figure 2: number 7). Supervisors were able to select ideas from a list uploaded by students.

\section{3) Auto match}

The system matched students and supervisors automatically. An automatic match considered more rules than the ones visible to administrators and could only be changed by a system developer. For example, Master's theses were matched before Bachelor's, and supervisors who had more available supervisions were matched first if the points were equal. Auto match was triggered by administrators (Figure 2: number 8) and generated a match that could be investigated manually before saving. The algorithm could be changed when necessary for a more appropriate matching result.

\section{4) Administrators selected}

Unit administrators allocated thesis projects to supervisors manually by allocating numbers and persons in the system, Figure 2 number 9 illustrates this method, and only if direct contact between students and supervisors is insufficient. Administrator matching in the system could be done fast and easily when the administrator had good knowledge about the supervisors.
Direct matching further facilitated the introduction of an instant notification system. Notifications told supervisors when students added ideas that matched a supervisor's area of interest. Also, when supervisors added ideas, the system generated messages to students who had similar research interests. This was an additional option for making ideas noticeable quickly and increasing the number of direct matches in the system.

All four methods had inherent pros and cons, as summarized in Table 3. It was assumed that the first and second methods contributed more than the other two methods from a motivational perspective. Arguably, a supervisor or student selected an idea because of his or her motivation. The publisher of that idea was already motivated, and when he or she was matched with a motivated partner, it constituted the highest level of motivation that could be expected from the perspective of students and supervisors. There was no external force or intervention for selecting and matching ideas, and SciPro provided the necessary infrastructure for direct selection. Figure 7 illustrate this selection. Although auto matching was fast and impersonal, the main problem was inappropriate keywords for ideas and research areas. Students could have selected the wrong research area and/or keyword and found it hard to locate good matching criteria that reflected their research interest. The administrator assign method was the last solution when other methods were not applicable. Figure 8 depicts manual-matching method. The issues with this method were middleman involvement, high workload, and also the need for an administrator with good knowledge of all supervisors and keywords.

Originally the supervisors had to accept or reject the suggested ideas. Since many supervisors were slow to accept the project ideas, the settings were changed so that the supervisor received the project ideas directly without the chance to accept or reject.

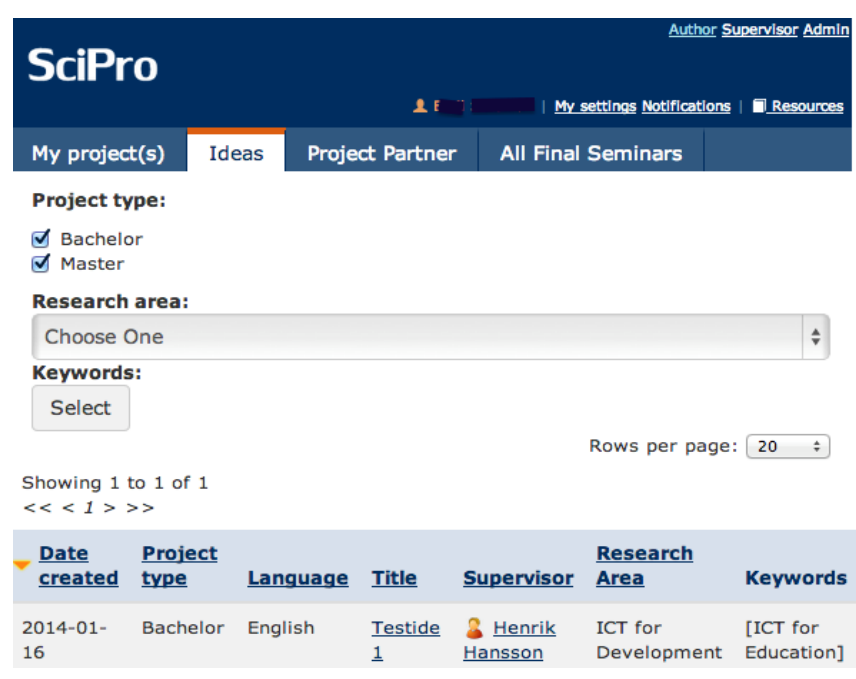

Fig. 7 Screen shot: 'Select idea'

Additionally, in version 3, the idea bank was more integrated so that matching occurred immediately when students selected a supervisor's idea. At the same time, the supervisor spent less time on supervision and this was automatically registered in the system. 


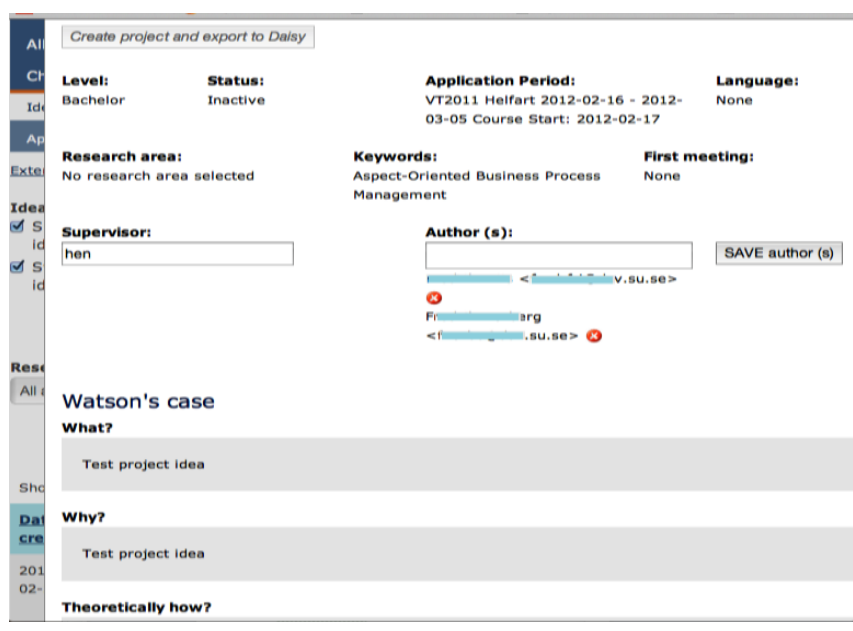

Fig. 8 Screen shot: 'Manual match'

Figure 9 sources hold and as shown in Table 1, the system matched a considerable number of students, project ideas, and supervisors. With a manual mode of operations it would take several months to administer the documents and communicate with all actors. Furthermore, the system was up to date in real time and transparent regarding who was allocated to supervise whom and what topics were suggested.

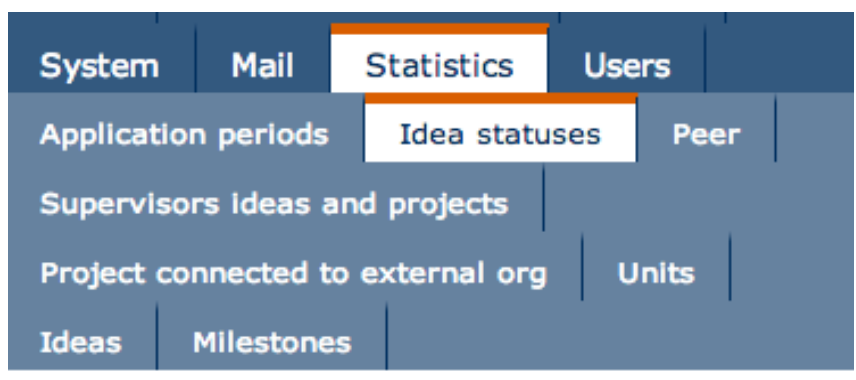

\begin{tabular}{llll} 
Status & Total & Bachelor & Master \\
Pending & 0 & 0 & 0 \\
Unmatched & 230 & 125 & 105 \\
Matched, no project & 216 & 127 & 89 \\
Matched, has project & 383 & 292 & 91 \\
\hline Inactive & 32 & 13 & 19 \\
\hline
\end{tabular}

Fig. 9 Screen shot: 'Match status'

The number of ideas matched in the system, moving from a student 'door knocking' mode (asking supervisors if they could supervise), which was unstructured, time-consuming, and also frustrated both students and supervisors, to a more flexible and informative IT-support system, needed further attention. A number of activities, processes, and functions were identified based on needs expressed by students, supervisors, and administrators. The needs were prioritized in the following order; students' needs first, supervisors needs second, and administrators' needs third. The department benefited from this system since was easily accessible and maintainable.

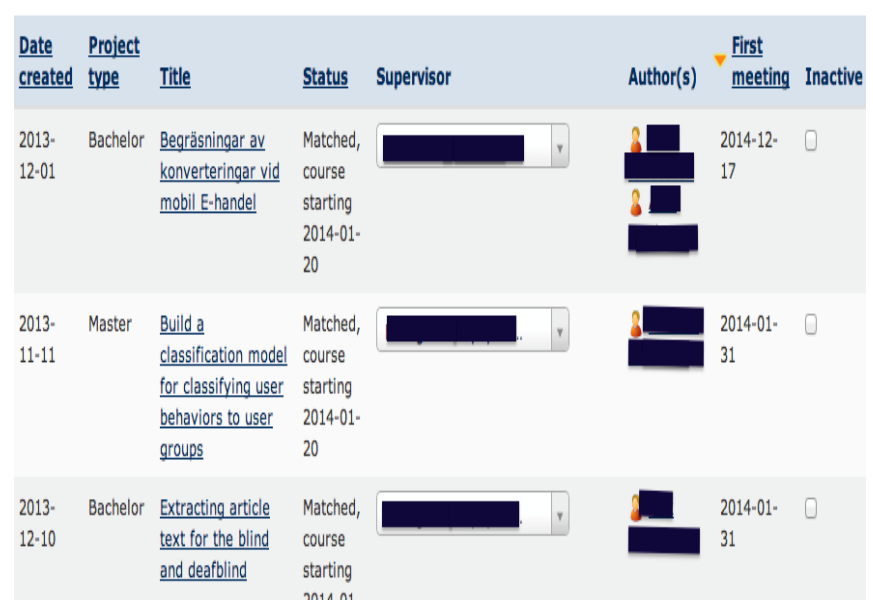

Fig. 10 Screen shot: 'Matched project details'

When the supervisor agreed to supervise a student, he/she could disclose his/her identity to the student before the course started. Otherwise, it would be released in the system automatically and be visible to the student when the course started. It was a problem in version 1 and 2 that a few supervisors did not contact their students in time and the students did not know who their supervisors were. This caused a lot of student frustration and some internal staff conflicts; how long should a supervisor wait to respond? who was responsible for correcting it? A re-allocation of supervisors was not possible because of a resource shortage regarding available supervisors and management time. Also, a new feature in version 3 introduced a built-in template for a 'first meeting' at course start, when the supervisor filled in the date and location of the meeting, since in some cases, the first meeting had been significantly delayed (Figure 2: number 10). Now non-implemented first meetings were visible in the system and actions could be taken in time to prevent delays (see Figure 10). In version 3, the integration was more complete, including automatic registration of new projects in the administrative system (DAISY), which in earlier versions had to be done separately by supervisors. This registration was necessary because otherwise: (1) the project would not be officially started, (b) grading could not take place, and (3) students could not get access to the subsequent support functions in SciPro.

The actual project plan was written with the help and advice of the allocated supervisor. Students wrote a research plan between one and a half and three pages long (Figure 2: number 11) with the following structure: (1) preliminary title, (2) background, (3) aim and research questions/problem statement, (4) methods and material, (5) expected results, (6) significance, (7) time and activity plan, and (8) references. Once the supervisor approved this plan (Figure 2: number 12) the student proceeded to the next step (description is not within the scope of this article).

\section{The Supervision Support System}

Once a new project was registered both supervisors and students could start communicating in the thesis support system. The IT support developed to facilitate the supervision process is not within the scope of this article but see Hansson [25], Hansson and Moberg [26], Hallberg, and colleagues [27], Larsson and Hansson [28], and Hansson and colleagues [9]. 


\section{SciPro Resources}

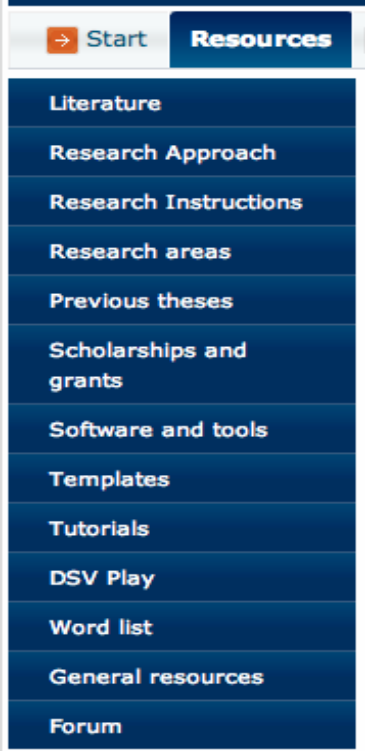

Evaluations revealed that better communication between supervisors, reviewers, and students was needed. The matching of reviewers (senior academics acting as mentors and evaluators) has recently been implemented, but only manual matching by an administrator so far.

In addition to the features discussed above, SciPro provides a unique space for organizing useful resources for starting a quality thesis. The information and resources section has a collection of information and tools that can be used by students to meet their requirements. Figure 11 shows a summary of resources available in the current system.

\section{CONCLUSIONS}

In order to produce a good thesis, a good start is very important. Student-idea-supervisor matching is the essence of starting a good thesis and the administration of this process is very complex. Although information technology is widely used in higher education, there is a lack of IT support in thesis supervision. SciPro is suggested as a model for discussion, and future developers should be able to enhance the features elaborated in this discussion. An Internet-based idea bank as a repository for ideas and as a management system to facilitate matchmaking between students and supervisors is an important initial part in the process of creating quality theses. The idea bank can be linked with external sources to enhance the richness of ideas.

Matching is a complex process, and information technology can be used to manage this process and reduce the burden of administration. SciPro is a model work for matchmaking and can be developed to meet future needs. In addition to the technical aspects, human behaviour is very important for the smooth functioning of the system. Hence it is essential to consider the stakeholders' requirements and fine-tune the system to match requirements as much as possible. Students and supervisors who can select each other based on mutual interests (ideas) directly (without a middle man/administrator) is the best procedure from a motivational perspective. Auto match is fast but could be problematic because of inappropriate keyword selection by the students. Although administrative selection is comparatively problematic, it is the best solution when other methods are not applicable. Policy on procedures is also an important factor; it includes deciding on rules and regulations, roles and responsibilities as well as incentives and the consequences of not complying. SciPro creates an ICTenabled supporting environment for four different matching methods between students and supervisors, depending on policy. The analysis shows that SciPro is an ICT-enabled, flexible structure which supports the starting stage of many theses with quality and efficiency.

\section{ACKNOWLEDGEMENTS}

The authors would like to thank Khalid Bencherifa for the artistic design of the figures 'Idea bank' and 'Research approaches' and William Jobe for language corrections. They also thank staff and students at the Department of Computer and Systems Sciences for their valuable feedback and participation. 


\section{REFERENCES}

[1] S. A. Lei, "Strategies for finding and selecting an ideal thesis or dissertation topic: A review of literature," Coll. Stud. J., vol. 43, pp. 1324-1332, 2009.

[2] D. J. Isaak and W. A. Hubert, "Catalyzing the Transition from Student to Scientist: A Model for Graduate Research Training," Bioscience, vol. 49, no. 4, p. 321, Apr. 1999.

[3] N. F. Foster and S. L. Gibbons, Studying Students: The Undergraduate Research Project at the University of Rochester. Assoc of Cllge \&amp; Rsrch Libr, 2007, p. 99.

[4] M. E. Harrison and W. B. Whalley, "Undertaking a Dissertation from Start to Finish: The Process and Product," J. Geogr. High. Educ., vol. 32, no. 3, pp. 401-418, Sep. 2008.

[5] M. Richard, "A Research project supervision system. Makerere University, Uganda.," 2008. [Online]. Available:

http://dspace.mak.ac.ug/handle/123456789/627 . [Accessed: 18-Jul-2012].

[6] S. Colbran, "Collaborative Supervision of Legal Doctoral Theses Through E-learning," Univ. New Engl. Law J., vol. 1, no. 1, 2004.

[7] M. de Beer and R. B. Mason, "Using a blended approach to facilitate postgraduate supervision," Innovations in Education and Teaching International, vol. 46. pp. 213-226, 2009.

[8] K. MacKeogh, "Supervising undergraduate research using online and peer supervision," 2006. [Online]. Available: http://doras.dcu.ie/82/. [Accessed: 11-Jul2012].

[9] H. Hansson, J. Collin, K. Larsson, and G. Wettergren, "Sci-Pro improving universities core activity with ICT supporting the scientific thesis writing process," in Sixth EDEN Research Workshop - Budapest, 2010, 2010.

[10] N. Aghaee, U. Larsson, and H. Hansson, "Improving the Thesis Process," su.diva-portal.org, 2008. [Online]. Available: http://iris.im.uu.se/wpuploads/2012/08/iris2012_submission_66.pdf. [Accessed: 30-Jan-2014].

[11] J. G. Donald, A. Saroyan, and D. B. Denison, "Graduate student supervision policies and procedures: A case study of issues and factors affecting graduate study," Can. J. High. Educ., vol. 25, no. 3, pp. 71-92, 1995.

[12] T. W. Maxwell and R. Smyth, "Research supervision: the research management matrix," High. Educ., vol. 59, no. 4, pp. 407-422, Sep. 2009.

[13] R. W. Connell, "How to supervise a PhD," vol. 28, no. 2, pp. 38-42, 1985.

[14] R. Sherman and R. Webb, Qualitative Research in Education Focus and Methods. London; New York: Falmer Press, 1988, p. 217.

[15] M. McCaslin and K. Scott, "The five-question method for framing a qualitative research study," Qual. Rep., vol. 8, no. 3, pp. 447-461, 2003.

[16] J. W. Creswell, W. E. Hanson, V. L. Clark Plano, and A. Morales, "Qualitative Research Designs: Selection and Implementation," Couns. Psychol., vol. 35, no. 2, pp. 236-264, Mar. 2007.
[17] R. Stake, "The art of case study research," 1995.

[18] T. Kuhn, The structure of scientific revolutions (3rd ed.). Chicago, IL, US: University of Chicago Press, 1996, p. 212

[19] I. Niiniluoto, "The aim and structure of applied research," Erkenntnis, vol. 38, no. 1, pp. 1-21, 1993.

[20] Alan Hevner and S. Chatterjee, Design research in information systems: theory and practice. Springer, 2010.

[21] K. Peffers, T. Tuunanen, M. a. Rothenberger, and S. Chatterjee, "A Design Science Research Methodology for Information Systems Research," J. Manag. Inf. Syst., vol. 24, no. 3, pp. 45-77, Dec. 2007.

[22] "Laws and Regulations - Swedish National Agency for Higher Education." .

[23] H. Hansson, J. Moberg, and R. Peiris, "How to use SciPro. An IT-support system for Scientific Process: management of Ideas to finished theses," in International Conference on Advances in ICT for Emerging Regions, 2012, pp. 111-121.

[24] T. J. Watson, "Managing, Crafting and Researching: Words, Skill and Imagination in Shaping Management Research," Br. J. Manag., vol. 5, no. s1, pp. S77-S87, Dec. 1994.

[25] H. Hansson, "4-excellence: IT system for theses," in Going Global - Internationalishing higher education, 2012, pp. 13-15.

[26] H. Hansson and J. Moberg, "Quality processes in technology enhanced thesis work," in 24th ICDE World Conference on Open and Distance Learning, 2011, pp. 2-5.

[27] D. Hallberg, H. Hansson, J. Moberg, and K. P. Hewagamage, "SciPro from a mobile perspective: Technology enhanced supervision of thesis work in emerging regions," in Aitec East Africa ICT summit, 2011, pp. 2-3.

[28] K. Larsson and H. Hansson, "The Challenge for Supervision: Mass Individualisation of the Thesis Writing Process with less Recourses," in Online Educa Berlin 2011 - 17th International Conference on Technology Supported Learning \& Training, 2011. 